\title{
Evaluation of Nematicidal Action of Some Bio-agents and Botanicals for Eco-friendly Management of Root-Knot Nematodes, Meloidogyne incognita on Tomato
}

\author{
Metasebia Terefe* \\ Ethiopian Institute of Agricultural Research, Melkassa Agricultural Research Center, \\ P.O. Box: 436, Nazareth Ethiopia
}

\begin{tabular}{|c|c|}
\hline Abstract & Article Information \\
\hline 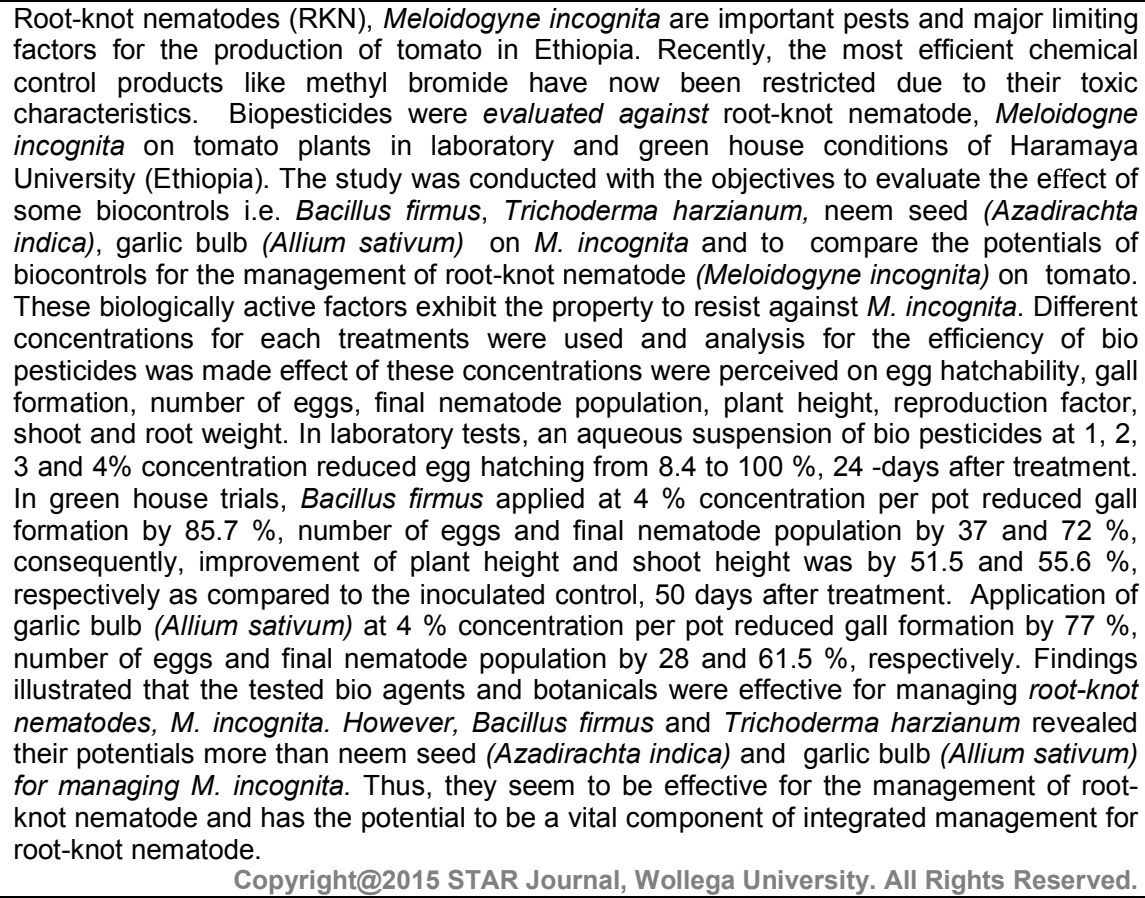 & $\begin{array}{l}\text { B. firmus } \\
\text { T. harzianum } \\
\text { A. indica } \\
\text { A. sativum } \\
\text { M. incognita } \\
\text { Tomato } \\
\text { Root-knot nematodes } \\
{ }^{*} \text { Corresponding Author: } \\
\text { Metasebia Terefe } \\
\text { E-mail: } \\
\text { metasebiaterefe@gmail.com }\end{array}$ \\
\hline
\end{tabular}

\section{INTRODUCTION}

Root knot nematodes (Meloidogyne sp.) are sedentary endoparasites and are among the most destructive pests of agricultural crops. They are worldwide in distribution having a very wide host range. Average crop losses due to these nematodes in the tropical and sub-tropical countries are $15 \%$ annually. However, in vegetable crops, these losses may reach up to $50-80 \%$. It has been estimated that in tomato fields $30 \%$ plants are affected by root knot nematodes and in certain areas, the tomato cultivation has been abandoned due to very poor yields on account of this disease (Agrios, 2004). Chemical agents such as carbofuran are effective in the management of nematodes but are not ecofriendly and in the course of time may cause serious threat to the ecological balance. Also there has been a de-registration of some hazardous nematicides. Increasing pressure is on farmers to use non-chemical pest control methods that do not pollute the environment. This emphasis the need for new methods of control such as the use of bio pesticides. Bio pesticides are various natural substances including natural enemies (bio agents) and plant compounds (botanical) that act against the pest and do not cause toxicities to the crop, thereby considering as a solution for nematode control in tomato.

Now a day, the use of bio pesticides for controlling Meloidogyne incognita is becoming appealing because of the growing problem of environmental pollution arising from the use of persistent pesticides. Many bacterial and fungal agents have been examined over a period of time for their potential as biocontrol agents. Bio agents such as, Psudomonas fluorescens has been studied widely and 
Metasebia Terefe

formulations containing this bacterium are used as a biopesticides against nematodes in many crops. The bacteria might produce compounds antagonistic to other soil microbes, such as phenazine-type antibiotics or hydrogen cyanid. Trichoderma viride, another agent used widely to control nematodes, is a fungus which colonizes near the plant roots and grows on roots, provide resistance to wilt and rot diseases and cause a physical barrier for nematodes to contact, and enhance the plant's root growth and nutrient absorption. Nematicidal activity of of T.viride may be due to the eggs and larvae being infected through the increase in chitinase and protease activity. As chitin is a major component of egg shell of nematodes, nematophagous egg parasitic fungus can penetrate the eggs leading to the reduction in population. (Wickramaarachchi and Ranaweera, 2008).

Efficacy of various plant extracts in nematode control has been studied. Neem, Azadirachta indica, is known to possess potential nematicidal compounds. Azadirachtin is the major nematotoxic compound in neem and all other nematotoxic compounds are released through volatilization, exudation, leaching and decomposing of the plant parts (Nanjegowda et al., 1998). The nematicidal effect of garlic has been reported. Garlic (Allium sativum) leaf extract has been successfully used to increase Tylenchulus semipenetrans mortality at high concentrations in laboratory conditions. Garlic has indirect effects on nematode populations because it disrupts their mobility, food absorption and reproduction. Garlic oil has been shown to offer significant protection against freeliving soil inhabiting nematodes (Block, 2010). Studies on the identification and use bio agents and botanical extracts for the control of nematodes, or integrated with other methods of control, are current areas of research in plant nematology. Thus, the objective of this study was to (i) evaluate the effect of some bio agents and botanicals on $M$. incognita (ii) compare the potentials of bio agents and botanicals for the control of root-knot nematodes (Meloidogyne incognita) in tomato.

\section{MATERIALS AND METHODS}

\section{Description of the Experimental Site}

Experiments were conducted at Haramaya University (HU). $\mathrm{HU}$ is located at $9^{\circ} 26^{\prime} \mathrm{N}, 42^{\circ} 3^{\prime} \mathrm{E}, 1980$ meter above sea level, Eastern Hararghe, Oromiya, Ethiopia. The site has a bimodal rain fall distribution pattern and is representative of a sub-humid, mid-altitude agro-climatic zone. The average annual rainfall is $760 \mathrm{~mm}$ and the mean annual temperature is $17{ }^{\circ} \mathrm{C}$ with a range of $14{ }^{\circ} \mathrm{C}$ to $18{ }^{\circ} \mathrm{C}$. The mean annual rainfall is $520 \mathrm{~mm}$ and mean maximum and minimum temperature range from $28.1^{\circ} \mathrm{C}$ to $34.6{ }^{\circ} \mathrm{C}$ and $14.5{ }^{\circ} \mathrm{C}$ to $21.6{ }^{\circ} \mathrm{C}$, respectively (Belay, 2002).

\section{Establishment of Root-knot Nematodes (Meloidogyne incognita) Culture}

Tomato plants infected with root-knot nematodes (Meloidogyne incognita) were collected from a vegetable farm in the Haramaya University (HU), Ethiopia. Egg masses were picked up from the infected roots using forceps and a needle and then allowed to hatch. Juveniles were inoculated around the roots of tomato seedlings (cv. Marglobe) raised in sterilized soil in pots. This was sub cultured to maintain sufficient numbers of root-knot nematodes for subsequent experiments.
Sci. Technol. Arts Res. J., July-Sep 2015, 4(3): 71-78

\section{Preparation of Bio-agents}

Fungal culture preparation sample of Trichoderma harzianum and Bacillus firmus (BioNem) were obtained from Plant Pathology Department, Haramaya University. Trichoderma harzianum was cultured on potato dextrose agar (PDA). The petridishes were then placed in an incubator at $25^{\circ} \mathrm{C}$. Spores were separated from mycelia by sieving through a $50 \mu \mathrm{m}$ sieve. The spore suspensions were then adjusted to the desired concentration after counting spore density using a haemocytometer. Serial dilutions of $T$. harzianum culture filtrates in water were prepared subsequently. Whilst, in $B$. firmus, it was available in powder in the form of BioNem. Different concentrations were prepared.

\section{Preparation of Plant Extracts (Botanicals)}

The neem seed (Azadirachta indica) and garlic bulb (Allium sativum) were used for the experiment. For the preparation of aqueous extracts the following procedures were used. The collected materials were dried under shade then it was grinded by pestle and mortar. About 20 $\mathrm{g}$ powder of each botanical was soaked separately in 100 $\mathrm{ml}$ of distilled water for 12 hours in $500 \mathrm{ml}$ Erlenmeyer flasks. After 12 hours of soaking they were filtered and the filtrate was then centrifuged at $3000 \mathrm{rpm}$ for $10 \mathrm{~min}$ for laboratory experiment. Then variable concentrations of botanicals were prepared.

\section{Experiment-I: Effect of Bio agents and Botanicals on Egg Hatching of $M$. incognita In vitro}

\section{Egg Mass Collection}

About 60-day-old tomato (cv. Marglobe) roots that were heavily infected with root-knot nematodes were collected from the HU vegetable farm. Two hours after collection, roots were brought to the Plant Pathology Laboratory of $\mathrm{HU}$, and washed gently using tape water. Using a sterile dissecting needle and forceps the egg masses were separated from the roots, and kept in refrigerator at $10{ }^{0} \mathrm{C}$ for one day to prevent hatching before application of treatments.

\section{Treatment Application}

Four concentrations namely; 1, 2, 3 and $4 \%$ of bio agents ( $T$. harzianum and $B$. firmus) and botanicals (Azadirachta indica and Allium sativum) were prepared by adding about 99, 98, 97, and $96 \mathrm{ml}$ of sterile water to beakers containing the four respective concentrations. The suspension was shaken by hand and kept at room temperature $\left(20-23^{\circ} \mathrm{C}\right)$ in the laboratory for $10 \mathrm{~h}$. About $5 \mathrm{ml}$ of different treatment suspension was added to a sterile Petri dish (9 $\mathrm{cm}$ diameter). Five equal sized egg masses were randomly picked using sterile forceps and were placed in each Petri dish containing the suspension. Egg masses kept in sterile water were used as a control. The Petri dish containing the suspension and the egg masses were kept at room temperature on the laboratory bench. The experiment was laid out in completely randomized design (CRD) with three replications. Mean average, maximum and minimum temperature were 19 , 23 and $15{ }^{\circ} \mathrm{C}$, respectively.

\section{Data Collected}

Seventy-two hours after treatment application, the Petri dishes were shaken, the suspension containing the nematodes was transferred to a counting dish, and nematode juveniles were counted using stereoscopic microscope at magnification of $50 \mathrm{X}$. Fresh suspension was added to the egg masses and kept for hatching again 
Metasebia Terefe

at room temperature. This was done every $72 \mathrm{~h}$, till hatching ceased in the control.

\section{Data Analysis}

Data on number of hatched second stage juveniles were normalized before analysis using square root transformation with the formula $(x+0.5) 1 / 2$ where $x$ is the number of juveniles and 0.5 is constant number to be added (Gomez and Gomez, 1984). The transformed values were subjected to analysis of variance (ANOVA) procedures using Statistical Analysis Software (SAS) (version.9.00, SAS. Institute Inc., Cary, NC, USA). Treatment means were separated using the least significant differences (LSD).

Experiment-II: Effect of Bio-agents and Botanicals on Root-knot Nematodes, $M$. incognita infestation and Growth of Tomato Plants under the Greenhouse Condition

The effect of biological and botanical on root-knot nematodes, $M$. incognita infestation and growth of tomato was tested in the green house.

\section{Treatments and Experimental Design}

There were a total of 10 treatment combinations i.e. 4 treatments each have 2 levels. There were also two controls: un inoculated control and inoculated control. In uninoculated control, neither the nematode nor the treatment was applied; whilst in inoculated control, the nematode was applied but the treatment was not. The experiment was laid out in a randomized complete block design (RCBD) with three replications.

\section{Treatment Application}

Seeds of tomato (cv. Marglobe) were sown in sterile soil in plastic trays under the greenhouse. A 1-month-old seedling was transplanted into each pot containing 1200 cc of sterilized soil with 1:2:3 proportions of sand, compost and clay, respectively. A week after transplanting, the soil around the seedlings was inoculated with $M$. incognita at 1000 juveniles per plant. Two concentrations were used. These were 3 and $4 \%$. Each treatment was applied to a tomato seedling in a pot a week after transplanting. Seedlings were watered as needed.

\section{Data Collected}

The following data were collected 50-days after treatment application. The number of galls per plant was counted manually. Average of 10 egg masses per plant were randomly taken using sterile forceps and dissecting needle. The egg masses were vigorously shaken with $5 \%$ sodium hypochlorite in stoppered flasks for 2 min based on the procedure of Hussey and Barker (1973). From the total suspension, a 3-ml suspension was pipetted into a counting dish and the numbers of eggs were counted using a stereomicroscope at a magnification of 50X. The length of the plant was measured for each pot from the soil line to the tip of the stem and expressed in $\mathrm{cm}$. The plants were cut at the crown level and the shoot weight was measured using electronic balance. The plant roots were removed from the soil and gently washed with distilled water to remove soil particles and the weight of the roots was recorded using an electronic balance. The soil samples were collected from each pot using a labeled paper bags and taken to a laboratory. Final population density of nematode was determined based on the Baermann funnel technique (South- ey, 1970). The
Sci. Technol. Arts Res. J., July-Sep 2015, 4(3): 71-78

reproduction factor $(\mathrm{RF})$ was also calculated by dividing the final population (pf) with the initial population (pi).

\section{Statistical Analysis}

The data on plant height, shoot and root weight were directly analyzed according to the standared analaysis of variance (ANOVA), whereas number of galls, number of eggs/egg masses and final nematode population/pot were square root transformed before analysis to normalize variances with the formula $(x+0.5) 1 / 2$ where $x$ is the number of number of galls, number of eggs/egg masses and final nematode population/pot and 0.5 is constant number to be added (Gomez and Gomez, 1984). Then the data were subjected to analysis of variance (ANOVA) using Statistical Analysis Software (SAS, 2002) (version 9.00, SAS, Institute Inc., Cary, NC, USA). Treatment means were separated using the least significant differences (LSD).

\section{RESULTS AND DISCUSSION}

Experiment I: Effect of Bio-agents and Botanicals on Egg Hatching of $\boldsymbol{M}$. incognita in Laboratory

Root knot nematodes (RKN) are responsible for $12.3 \%$ yield loss of the world's major crops and global tomato production is affected by the genus Meloidogyne, the most economically important nematode in tropical and subtropical agriculture which reduces yield by $30-50 \%$ (Jonathan et al., 2001).

Applications of bio agents and botanicals at all concentrations were significantly $(p<0.05)$ inhibited egg hatching of $M$. incognita from egg-masses as compared to the control (Figure 1 and Table1). However, there was variation among the treatments in reducing hatching of eggs from egg masses. Treatments applied at lower concentrations were less effective than higher concentration in all tested treatments. Interfering with the life cycle of root-knot nematode by managing egg masses prior to hatching is important. From a single egg mass up to 500 juveniles can hatch and infect the same root or roots nearby and start a new life cycle (Dropkin, 1989).

The highest percentage of hatching inhibition (94.5\%) was obtained at the lower concentration from B.firmus followed by T.harzianum (73.3\%) over the control. The present studies parallel with the results obtained by Zdarska et al. (2001), a certain strains of Bacillus sphaericus and Bacillus laterosporus which inhibits egg hatch of parasitic nematodes in their host animals have been patented. Nematode egg shells consists of three layers namely, vitelline, chitinous and lipid layers. It might be possible that $B$. firmus secretes some toxins, which damages the egg shell of root-knot nematode. The hatching inhibitory and egg disintegrating effect of BioNem might be due to certain toxic substances present in the product or secreted by $B$. firmus that possess ovicidal property. Pure culture filtrates of $B$. firmus reduced $M$. incognita egg hatching. T.harzianum as an effective egg parasite of M.incognita. T.harzianum was able to grow on the egg surface and penetrated the egg shell (Sikora, 2008)). The present study may indicate that $B$. firmus and T.harzianum is an egg parasite of root knot nematode.

On the other hand neem seed (Azadirachta indica) and garlic bulb (Allium sativum) gave 41.4 and $8.4 \%$ of hatching inhibition of eggs from egg masses, respectively at lower concentration as compared to control (Figure 1 


\section{Metasebia Terefe}

and Table 1). Application of treatments Azadirachta indica at $4 \%$, T.harzianum at $3 \%$ and B.firmus at $1 \%$ inhibit the hatching of eggs of M.incognita at par amount (95\%) as compared to the control. Percent inhibition of egg hatching ranged from 8.4 to $100 \%$. Applications of B.firmus at $4 \%$ concentration caused $100 \%$ inhibition. Garlic (Allium sativum) has been successfully used to increase Tylenchulus semipenetrans mortality at high concentrations in laboratory conditions. Garlic has indirect effects on nematode populations because it disrupts their mobility, food absorption and reproduction. Garlic oil has been shown to offer significant protection against freeliving soil inhabiting nematodes (Block, 2010).
Sci. Technol. Arts Res. J., July-Sep 2015, 4(3): 71-78

Neem, Azadirachta indica, is one of the most versatile trees with regard to germicidal activity against an array of microorganisms. Its leaves, bark, and seed kernels can be used in nematode management. Various compounds such as nimbin, nimbidin, azadirachtin, salannin, thionemon, and meliantriol occur in the seeds, leaves, and bark of neem in high concentrations and are responsible for the tree's antimicrobial and nematicidal activity. Powder from the seed kernels and leaves has been found to be suppressive against some nematodes (Alam, 1993).

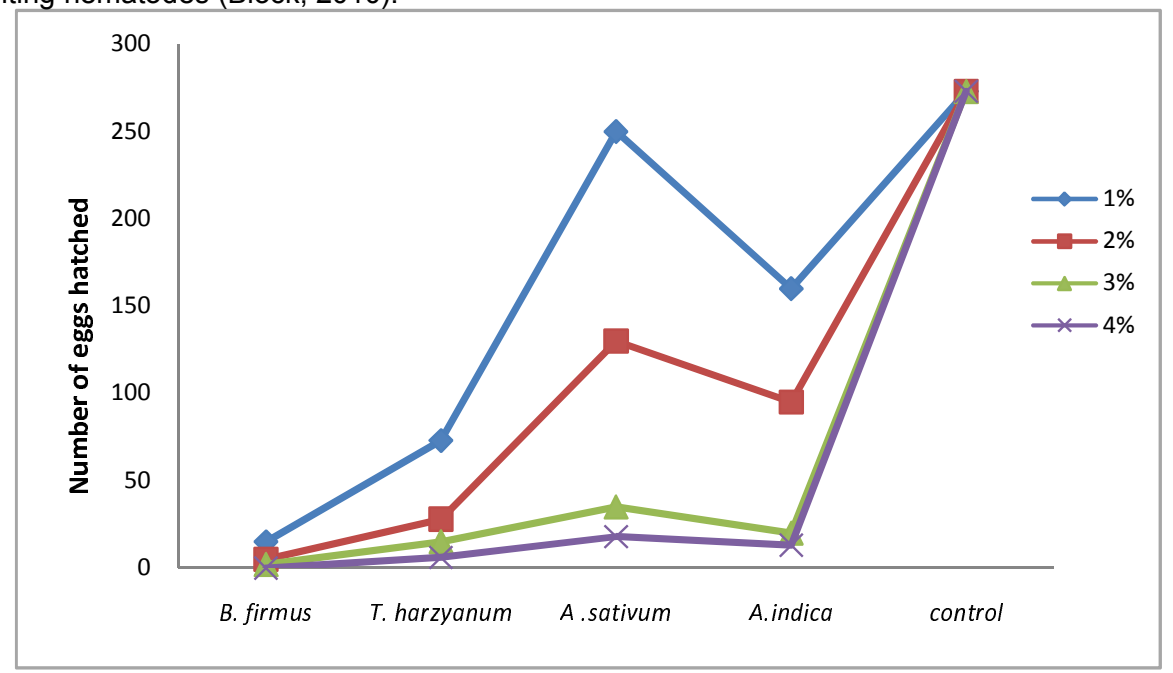

Figure 1: Effect of different concentration of Bio agents and Botanicals on rate of egg hatching in $M$. incognita in laboratory

Table 1: Effect of different concentrations of Bio agents and Botanicals on cumulative hatchability of egg masses of $M$. incognita 24-days after treatment application in laboratory

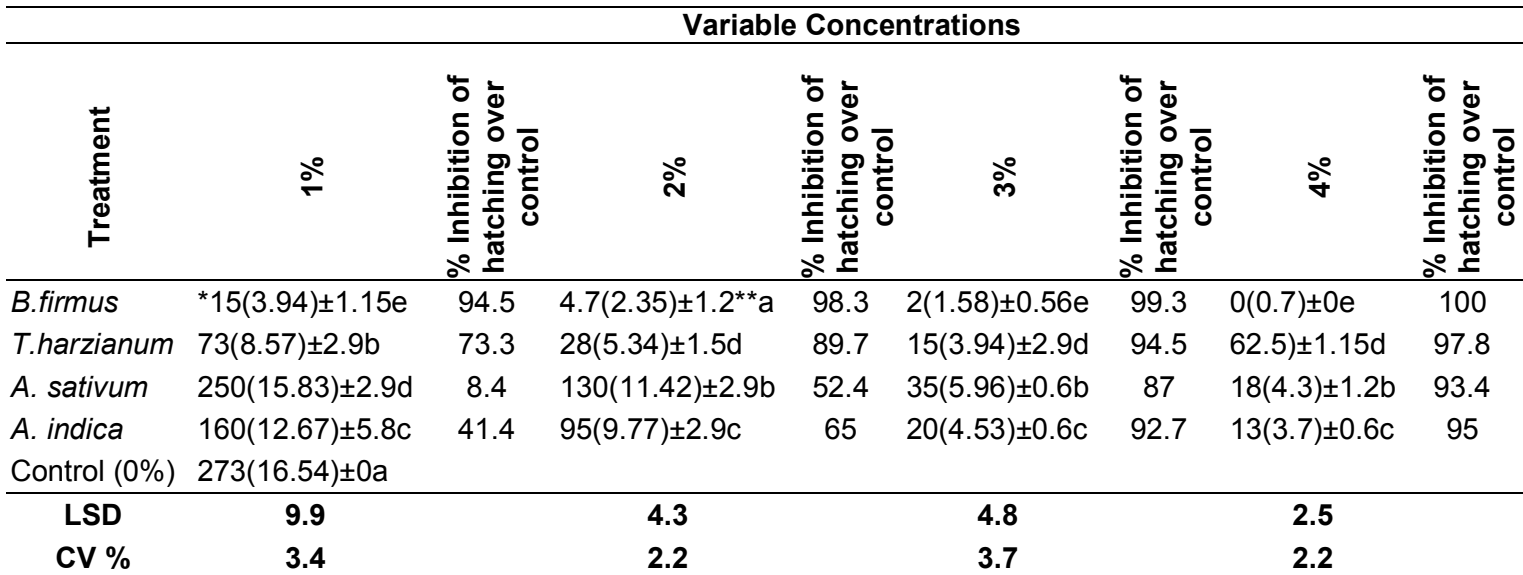

Means within the same column with a common letter are not significantly different $(P<0.05)$; *Figures in parenthesis are the transformed mean values (square root transformation were used with the formula $(x+0.5)^{1 / 2}$ ) and ${ }^{* *}$ Standard error of mean (SEm \pm ) CV $=$ Coefficient of variance, $\mathrm{LSD}=$ least significant differences at $\alpha 0.05$

Experiment II: Effect of Bio-agents and Botanicals on Nematode Infestation and Growth of Tomato Plants in the Green House

Root-knot nematodes are capable of harshly damaging a broad range of crops, in particular vegetables, causing dramatic yield losses mainly in tropical and sub-tropical agriculture (Sikora, 2008). This study was conducted with an aim to manage the root knot nematodes on the tomato plants here the effect of bio control agents i.e. Bacillus firmus, Trichoderma harzianum, Azadirachta indica and Allium sativum has been observed against Meloidogyne incognita in the green house of $\mathrm{HU}$. Comparison was done with the plants grown in controlled conditions and plants applied only with Meloidogyne incognita. Findings indicated that bio pesticides are the best way to control the root knot nematodes and it is safe and sound scheme for the environment as well. 
Metasebia Terefe

\section{Galls Formation}

Root-knot nematode (RKN), Meloidogyne incognita is manifested by the formation of galls in the root accompanied by stunted growth, chlorosis and loss of vigor of the plant (Babu et al., 1999). The bioagents and
Sci. Technol. Arts Res. J., July-Sep 2015, 4(3): 71-78

botanicals tested decreased the negative effects of nematodes, leading to a decrease in galling and an enhancement in the growth and yield of the tomato, but the effect varied according to the treatment and parameter (Table 2 and 3 ).

Table 2: Effect of Bio agents and Botanicals on infestation of $M$. incognita on tomato under the green house
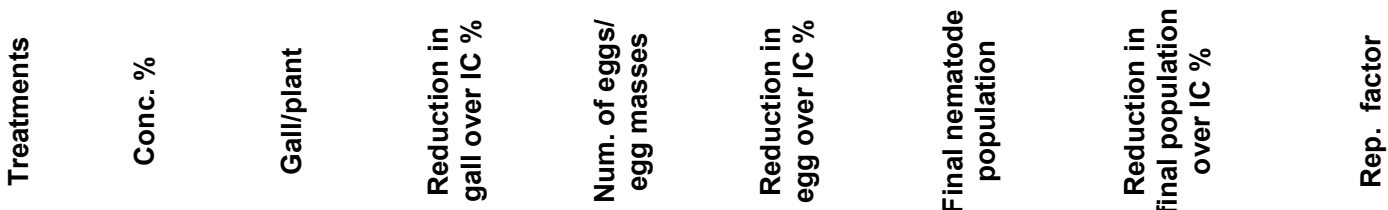

\begin{tabular}{cclclclcl}
\hline \multirow{2}{*}{ B. firmus } & 3 & ${ }^{*} 75(8.69) \pm 0.6 \mathrm{f}$ & 82.5 & $390(19.8) \pm 5.8^{* *} \mathrm{~g}$ & 33 & $93(9.7) \pm 1.7 \mathrm{e}$ & 68 & $0.093(0.77) \pm 0.001 \mathrm{~d}$ \\
& 4 & $61.7(7.89) \pm 6 \mathrm{~g}$ & 85.7 & $370(19.3) \pm 5.8 \mathrm{~h}$ & 37 & $80(9) \pm 3.6 \mathrm{f}$ & 72 & $0.08(0.76) \pm 0.005 \mathrm{e}$ \\
\multirow{2}{*}{ T. harzianum } & 3 & $87(9.35) \pm 0.6 \mathrm{ed}$ & 80 & $415(20.4) \pm 2.9 \mathrm{ed}$ & 29 & $109(10.5) \pm 5 \mathrm{~cd}$ & 62 & $0.11(0.78) \pm 0.003 \mathrm{c}$ \\
& 4 & $78(8.86) \pm 1 \mathrm{ef}$ & 82 & $405(20) \pm 2.9 \mathrm{f}$ & 30.8 & $95(9.8) \pm 2.9 \mathrm{e}$ & 67 & $0.095(0.77) \pm 0.001 \mathrm{~d}$ \\
\multirow{4}{*}{ A. sativum } & 3 & $105(10.27) \pm 2.9 \mathrm{~b}$ & 75.6 & $450(21) \pm 5.8 \mathrm{~b}$ & 23 & $123(11) \pm 8 \mathrm{~b}$ & 57.6 & $0.125(0.79) \pm 0.001 \mathrm{~b}$ \\
& 4 & $98(9.92) \pm 1 \mathrm{bc}$ & 77 & $420(20.5) \pm 2.9 \mathrm{~cd}$ & 28 & $111.7(10.6) \pm 6.7 \mathrm{bcd}$ & 61.5 & $0.113(0.78) \pm 0.004 \mathrm{c}$ \\
\multirow{2}{*}{ A. indica } & 3 & $92(9.62) \pm 1.5 \mathrm{~cd}$ & 78.6 & $425(20.6) \pm 2.9 \mathrm{c}$ & 27 & $115(10.8) \pm 2.9 \mathrm{bc}$ & 60 & $0.015(0.72) \pm 0.0006 \mathrm{f}$ \\
& 4 & $81(9.03) \pm 0.6 \mathrm{ef}$ & 81 & $410(20.3) \pm 2.9 \mathrm{ef}$ & 30 & $99(10) \pm 0.6 \mathrm{de}$ & 66 & $0.01(0.7) \pm 0 \mathrm{f}$ \\
\hline IC & 0 & $430(20.75) \pm 5.8 \mathrm{a}$ & - & $585(24) \pm 3 \mathrm{a}$ & - & $290(17) \pm 5.8 \mathrm{a}$ & - & $0.29(0.89) \pm 0.006 \mathrm{a}$ \\
UC & 0 & $0(0.71) \pm 0 \mathrm{~h}$ & - & $0(0.7) \pm 0 \mathrm{i}$ & - & $0(0.7) \pm 0 \mathrm{~g}$ & - & $0(0.7) \pm 0 \mathrm{~g}$ \\
\hline CV & & 4.5 & & $\mathbf{1 . 4}$ & & $\mathbf{6}$ & & 5
\end{tabular}

${ }^{*}$ Figures in parenthesis are the transformed mean values (square root transformation were used with the formula $(x+0.5){ }^{1 / 2}$ ) and ${ }^{* *}$ Standard error of mean (SEm \pm ); Means within the same column with a common letter are not significantly different ( $\left.p<0.05\right)$; CV =Coefficient of variance, $\mathrm{IC}=$ Inoculated control, UC=Uninoculated control

Table 3: Effect of Bio agents and Botanicals on growth and infestation of M.incognita on tomato under the green house

\begin{tabular}{lcccccc}
\hline Treatments & Conc \% & $\begin{array}{c}\text { Plant } \\
\text { height } \\
\text { (cm) }\end{array}$ & $\begin{array}{c}\text { Increase } \\
\text { in height } \\
\text { over IC (\%) }\end{array}$ & $\begin{array}{c}\text { Fresh } \\
\text { shoot } \\
\text { weight (g) }\end{array}$ & $\begin{array}{c}\text { Increase in } \\
\text { fresh shoot } \\
\text { weight over } \\
\text { IC (\%) }\end{array}$ & $\begin{array}{c}\text { Fresh root } \\
\text { weight }(\mathbf{g})\end{array}$ \\
\hline B.firmus & 3 & $48^{*} \pm 0.6 \mathrm{bc}$ & 45.5 & $81 \pm 0.58^{\star *} \mathrm{bc}$ & 50 & $28 \pm 0.58 \mathrm{de}$ \\
& 4 & $50 \pm 1.2 \mathrm{~b}$ & 51.5 & $84 \pm 2 \mathrm{~b}$ & 55.6 & $27 \pm 1 \mathrm{de}$ \\
T.harzianum & 3 & $43 \pm 1.7 \mathrm{~d}$ & 30 & $75 \pm 5.5 \mathrm{bcd}$ & 39 & $30 \pm 1 \mathrm{cde}$ \\
& 4 & $45 \pm 2.9 \mathrm{~cd}$ & 36 & $79 \pm 3 \mathrm{bc}$ & 46 & $29.5 \pm 1 \mathrm{cde}$ \\
A. sativum & 3 & $35 \pm 0.6 \mathrm{f}$ & 6 & $58 \pm 4 \mathrm{ef}$ & 7.4 & $40 \pm 2.9 \mathrm{~b}$ \\
& 4 & $37 \pm 0.6 \mathrm{ef}$ & 12 & $65 \pm 5 \mathrm{edf}$ & 20 & $35 \pm 2 \mathrm{bc}$ \\
A. indica & 3 & $40 \pm 3 \mathrm{ed}$ & 21 & $69 \pm 3.8 \mathrm{cde}$ & 28 & $33 \pm 2.5 \mathrm{~cd}$ \\
& 4 & $41 \pm 0.6 \mathrm{ed}$ & 24 & $73 \pm 2.5 \mathrm{bcd}$ & 35 & $31 \pm 2.3 \mathrm{~cd}$ \\
\hline IC & 0 & $33 \pm 1.7 \mathrm{f}$ & - & $54 \pm 2.3 \mathrm{f}$ & - & $48 \pm 2.3 \mathrm{a}$ \\
UC & 0 & $59.5 \pm 1.3 \mathrm{a}$ & 80 & $103 \pm 2 \mathrm{a}$ & 90.7 & $24 \pm 1.5 \mathrm{e}$ \\
\hline CV & & $\mathbf{6 . 3}$ & & $\mathbf{8 . 6}$ & & $\mathbf{1 1}$ \\
\hline
\end{tabular}

*Figures in parenthesis are the transformed mean values (square root transformation were used with the formula $(x+0.5)^{1 / 2}$ and ${ }^{* *}$ Standard error of mean $(\mathrm{SEm} \pm)$; Means within the same column with a common letter are not significantly different $(p<0.05) ; \mathrm{CV}=$ Coefficient of variance, IC=Inoculated control, UC=Un inoculated control

Application of treatments significantly $(p<0.05)$ reduced formation of galls (Table 3 ). The number of galls or knots on tomato was varied with type of treatment and concentration applied. Results revealed that extent of galls were statistically significant in $B$. firmus, $T$. harzianum, Neem seed and Garlic bulb (Table 2). Treatments applied at the rate of 3,4 and $4 \%$ concentration in B. firmus, $T$. harzianum and Neem seed provided similar results in reduction of gall formation respectively as compared to control. Maximum number of gall formation was seen from inoculated control (430) and the least number of gall formations (61.7) was observed from $B$. firmus at $3 \%$ concentration. The mean number of reduction in galls formation ranged from 85.7 to $75.6 \%$ as compared to galls in nematode-inoculated control. Babu et al. (1999) reported that the formation of galls on the roots and colonization of root tissue by this nematode deprives plants of nutrients. The damage also occurs due to devitalization of root tips, which may stop their growth or cause excessive branching of roots. The galls on the root system disturb important functions such as the uptake and transport of water and nutrients. 
Metasebia Terefe

\section{Production of Eggs per Egg Masses}

There were significant differences $(p<0.05)$ among treatments in formation of number of eggs per egg mass (Table 2).Treatments applied at different concentration adversely affected production of eggs. Maximum (37\%) reduction in egg production was achieved by $B$. firmus at $4 \%$ concentration and the least $(23 \%)$ reduction at $3 \%$ concentration was obtained from neem seed as compared to inoculated control. These findings confirm the results obtained by Akhtar and Mahmod (2000), with root dip treatment of tomato in leaf extracts of neem to prevent the M. incognita attack.

There was 585 number of eggs produced in inoculated control (Table 2). Application of B.firmus and $T$. harzianum at the rate of $4 \%$ gave similar results reduction in formation of eggs per egg masses. Species of genus (Trichoderma) have been used as natural control agent of different pathogens. Management of the soil has been done by $T$. harzianum and $T$. koningii for the diminution in egg assembly of Meloidogyne spp. (Sharon et al., 2001).

Saxena et al. (2000) reported the toxin producing rhizobacteria hold a good promise in reducing the damage caused by phytonematodes. These bacteria are easy to culture and can be produced in large quantity. Different concentrations of Pasteuria penetrans isolates have been used to control the production of galls and egg mass by M. javanica on the eggplant. Javed et al. (2006) reported that neem is one of the most effective agent against root knot nematode on the roots of tomato, neem formulations have been applied against root knot nematodes development of the second stage juveniles (J2) as soil drenching . Fadzirayi et al. (2010) stated that garlic disrupts nematode mobility, feeding and reproduction, the latter being a plausible explanation for the low reproduction rate.

Final Nematode Population and Reproduction Factor

Harmful effects of nematicides enable scientists to promote biopesticides against $M$. incognita. For different concentrations and treatments of bioagents and botanicals there were significant reduction of the nematode population over inoculated control at termination of the experiment $(p<0.05) \quad($ Table 2). However, significant differences $(p<0.05)$ among treatments were observed in reducing final nematode population, there were no significant differences $(p<0.05)$ between $B$. firmus at $3 \%$ and $T$. harzianum at $4 \%$ concentration in reduction of final nematode population. In addition, $T$. harzianum at $3 \%$, Neem seed at $3 \%$ and garlic bulb at $4 \%$ had the same effect in controlling the production of nematode population. Application of garlic gave equal results at 3 and $4 \%$ concentration for managing the final nematode population.

Rhizobacteria genera like Bacillus, Pseudomonas, and Azotobacter often colonize roots aggressively and have shown potential for biological control of plant pathogens both under in vitro and in vivo conditions Bacillus species like $B$. subtilus have been reported to be antagonistic against a number of pathogens. Three types of secondary metabolites have been identified as the nematicidal agents: ammonia, indole and stil bene derivative. They were found toxic to second-stage juveniles of root-knot nematode and to fourth-stage
Sci. Technol. Arts Res. J., July-Sep 2015, 4(3): 71-78

juveniles and inhibited egg hatching of $M$. incognita (Hu et al., 1999).

According to Sikora, 2008 beneficial fungi, for example Trichoderma spp., have been assessed for their antagonistic activity in opposition to plant pathogenic nematodes To reduce the plant parasitic root knot nematodes a wide range of fungal agents have been used.

The nematicidal activity of plant extracts may be due to the presence of active toxic pricnciple like azadirachtin and nimbin in Azadirachta indica. Such toxic principles might be absorbed by the plant roots which changes the chemical composition of plants and such roots excerted some influence on the pathogenesis of $M$. incognita as well as improved plant growth ( Javed et al., 2006).

Maximum reduction $(72 \%)$ of nematode population was recorded at $4 \%$ of $B$. firmus and the least reduction $(57.6 \%)$ from garlic applied at the rate of $3 \%$ and three percent concentration of garlic proved significantly $(p<0.05) \quad$ less effective than the other concentrations (Table 2).

Nematode reproduction factor (RF) is an indication of nematode multiplication. Increasing growth and decreasing RF suggest the nematicidal potential of treatments and similar observations are made by Abubakar et al. (2004). There was significant reduction in the reproduction parameters of $M$. incognita in plants treated with variable concentration in individual treatment.

Maximum reproduction (0.29) of M.incognita was observed on the roots of check plants (inoculated control). Minimum reproduction factor $(0.08)$ was recorded in application of $B$. firmus at $4 \%$ concentration as compared to inoculated control. Whilst, garlic at $3 \%$ concentration gave the least prevention of $\mathrm{M}$. incognita production (0.125) as compared to other concentration and inoculated control.

\section{Plant Height}

Root-knot nematode is well known to reduce the plant height. It affects plant growth due to their consumption of host assimilates, through interfering with water and nutrient uptake by deforming roots thus diminishing and blocking water and nutrients absorption and translocation; nematode infection may also negatively influence the production of phytohormones (Melakeberhan and Webster, 1993)

Significant differences $(p<0.05)$ were observed between treatments applied at different rates in affecting plant height, as compared to inoculated control (Table 3) There were no significant differences in 3 and $4 \%$ concentrations within $B$. firmus, $T$. harzianum, neem seed and garlic bulb in improving plant height. Application of garlic bulb at 3 and $4 \%$ concentration had similar results in improvement of plant. Maximum (80\%) increment of plant height was gained from un inoculated control. Among treatments, $B$. firmus at $4 \%$ concentration provided higher percentage of plant height improvement $(51.5 \%)$ as compared to inoculated control and the least $(6 \%)$ was recorded from garlic bulb at $3 \%$ concentration.

John and Hebs (2000) also reported that bare root dip of brinjal seedlings in neem leaf extract significantly 


\section{Metasebia Terefe}

reduced the gall index and increase the plant growth parameters significantly. Soil application of neem and caltropis leaf extract reduced the root knot nematode infestation in cowpea. The nematode infected plants incline unfit to absorb water and nutrients and other essential elements from soil leading to poor plant growth and yield losses.

\section{Shoot Weight}

Table (2) confirmed the effectiveness of bio agents and botanicals against the root knot nematode ( $M$. incognita). Increases in shoot growth are due to the reduction in nematode attack as evidenced by the low final nematode population density. It was assessed from the present investigation that plant growth parameters were enhanced significantly and also the reproduction of $M$. incognita was decreased due to application of bioagents and botanicals. Application of treatments to nematode inoculated tomato plants significantly $(p \leq 0.05)$ increases the fresh shoot weight over inoculated control (Table 3). However, variation between the treatments in improving shoot weight of tomato was observed. Similar effects were observed between $B$. firmus and $T$. harzianum in both concentrations for improving shoot weight of tomato as compared to inoculated control. In addition, $4 \%$ of garlic bulb and $3 \%$ concentration of neem seed in improving shoot weight had similar results. Maximum shoot weight $(90.7 \%)$ was recorded from uninoculated control and minimum $(7.4 \%)$ from garlic bulb at $3 \%$ concentration as compared to inoculated control.

The use of botanicals is one of the alternative methods suggested by nematologist for nematode control. Botanicals such as Azadirachta, Eucalyptus, Chrommelina, Sida acuta and Targetis have been found to be effective in the control of nematodes in tomato, cowpea and egg plant fields (Umar et al., 2010). These botanicals not only control nematodes but also improve the soil productivity and crop yield by several folds. Many researchers like Sikorq, (2005) studied the effect of Trichoderma on the development and growth of parasitic nematodes. The effect of $T$. viride and $T$. harzianum on $M$. incognita on tomato plants, they reported that the addition of Trichoderma improved the growth of plant seedling and the number of nematodes was significantly reduced. The effectiveness of $T$. harzianum on root knot nematodes on tomato has been reported.

\section{Root Weight}

Formation of galls on the roots and colonization of root tissue by this nematode deprives plants of nutrients (Bird, 1974). The damage also occurs due to devitalization of root tips, which may stop their growth or cause excessive branching of roots. There were significant $(p<0.05)$ differences between treatments in root weight reduction. However, $B$. firmus and $T$. harzianum had the same results in reduction of root weight as compared to nematode inoculated control in both concentrations (Table $3)$. Maximum reduction $(27 \mathrm{~g}$ ) of root weight among treatments was recorded from $B$. firmus at $4 \%$ concentration and the least $(40 \mathrm{~g})$ from garlic bulb at $3 \%$ concentration. Un inoculated plant had minimum root weight $(24 \mathrm{~g})$ and maximum root weight $(48 \mathrm{~g})$ was recorded from nematode inoculated control. Olubunmi and Rajani (2004) also reported that the galls on the root system disturb important root functions such as the uptake and transport of water and nutrients. The root
Sci. Technol. Arts Res. J., July-Sep 2015, 4(3): 71-78

weight of inoculated control plants was greater than treatment applied plants and un inoculated control. The difference in root weight was not related the weight of the shoot. This could be due to the formation of large number of galls on inoculated plants. The differences in root weight may be explained by gall development; gall mass being heavier than an equivalent linear length of similar non- galled roots.

\section{CONCLUSIONS}

The results of the study revealed that the Bio agents and Botanicals have the potential to regulate the population of root knot nematode, $M$. incognita by reducing egg hatching, caused larval mortality and reduced the population of nematodes in laboratory and green house conditions. However, to see their efficacy further research should be carried out to determine its efficacy under field conditions. Due to exorbitant cost of nematicidal chemicals and the environmental hazards they cause, it is high time to modify the nematode management options like bio agents and botanicals which are safer and cost-effective. Findings illustrated that the tested bio agents and botanicals were effective for managing root-knot nematodes, $M$. incognita. However, Bacillus firmus and Trichoderma harzianum revealed more potential than neem seed (Azadirachta indica) and garlic bulb (Allium sativum) for managing $M$. incognita. Thus, they seem to be effective for the management of root-knot nematode and have the potential to be a vital component of integrated management for root-knot nematode.

\section{Conflict of Interest}

None declared.

\section{REFERENCES}

Abubakar, U., Adamu, T. and Manga, S.B. (2004). Control of Meloidogyne incognita (Kofoid and White) chitwood (rootknot nematode) of Lycopersicon esculentus (tomato) using dung and urine. African Journal of Biotechnology 3(8): 379-381.

Agrios, G.N. (2004). Plant Pathology. Fourth edition. Academic Press, San Diego, California, USA. 63 5p.

Akhtar, M. (2000). Nematicidal potential of the neem tree Azadirachta indica (A.Juss). Integrated Pest Management. Reviews 5:57-66, 2000, Kluwer Acedemic Publishers, Netherlands.

Alam, M.M. (1993). Bioactivity against phytonematodes. In: Parmer BS, Randhawa NS, Kumar K. eds. Neem Research and Development. Society of Pesticide Science; pp.123-143.

Babu, A.M., Vineet Kumar and Tomy Philip (1999). Root knot nematode- A hard to kill parasite-study. Indian Silk 38: 1112.

Belay, A. (2002). Factors influencing loan repayment performance of rural women in eastern Ethiopia: The case of Dire Dawa Area. M.Sc Thesis presented to the School of Graduate Studies of Alemaya University.

Block, E. (2010). Garlic and Other Alliums: The Lore And the Science. The Royal Society of Chemistry. Cambridge.

Dropkin, V.H. (1989). The genera of phytonematodes. In: Introduction to plant Nematology. Wiley-Interscience Publication, pp.89-217. 


\section{Metasebia Terefe}

Fadzirayi, C.T., Masamha, B. and Mukutirwa, I. (2010). Efficacy of Allium sativum (Garlic) in Controlling Nematode Parasites in Sheep. International Journal of Research in Veterinary Medicine 8:3.

Gomez, K.A. and Gomez, A.A. (1984). Statistical Procedures for Agricultural Research, $2^{\text {nd }}$ Edn., John Willey and Sons, New York.

Hu, L.J. and Webster, J.M. (1999). Nematicidal metabolites produced by Photorhabdus luminescens (Enterobacteriaceae), bacterial symbiont of entomopathogenic nematodes. Nematology 1:457-469.

Hussey, R.S., Barker, K.R. (1973). A comparison of methods of collecting inocula of Meloidogyne spp. Including a new technique. Plant Disease Reporter 57: 1025-1028.

Javed, N., Gowen, S.R., Inam-ul-Haq, M., Abdullah, K. and Shahina, F. (2006). Systemic and persistent effect of neem (Azadirachta indica) formulations against root-knot nematodes, Meloidogyne javanica and their storage life. Crop Protectection 26(7): 911-916.

John, A. and Hebsy Bai. (2000). Bare root dip of brijal seedlings in phytochemicals for the management of root knot nematode (M. incognita). Journal of Tropical Agriculture 38(1/2): 69-72.

Jonathan, E.I., Kumar, S., Devarajan, K. and Rajendran, G. (2001). Fundamentals of Plant Nematology, Devi Publications, Tiruchirapalli.

Melakebrham, H., Webster, J.M. (1993). The phenology of plant-nematode interaction and yield loss. In M.W. Khan (ed.). Nematode interactions. University, Aligarh. India. Pp.26-41.

Nanjegowda D., Naik B.G., Ravi K., Reddy P.P., Kumar N.K.K. and Verghese A. (1998). Efficacy of neem products and a nematicide for the management of rootknot nema- tode Meloidogyne incognita in tomato nursery. Pp. 318-320. In: Advances in IPM for horticultural
Sci. Technol. Arts Res. J., July-Sep 2015, 4(3): 71-78

crops. Proceedings of the First National Symposium on Pest Management in Horticultural Crops: environmental implications and thrusts. 15-17 October 1997, Bangalore, India.

Saxena, A. K., Pal, K.K. and Tilak, K.V.B.R. (2000). Bacterial biocontrol agents and their role in plant disease management. In: R.R.Upadhyay, K. G. Mukerii, and B. P. Chamola, (eds.). Biocontrol potential and its exploitation in sustainable agriculture: Volume 1. Crop diseases, Weeds, and Nematodes. Kluwer Academy plenum, New York.

Sikora, R.A. (2008). Mutualistic endophytic fungi and in planta suppressiveness to plant parasitic nematodes. Biological Control 46(1): 15-23.

Sharon, E., Bar-Eyal, M., Chet, I., Herera-Estrella, A., kleifeld, O., Spigel, Y. (2001). Biological control of root knot nematode M.javanica by Trichoderma harzianum. Phytopathology 91:681-693.

Southy, J.F., 1970. Laboratory methods for work with plant and soil nematodes. H.M.S. office London.

Umar, I., Muhammad, Z. and Okusanya, B.A.O. (2010). Effect of organic amendments on the control of Meloidogyne javanica (Kofoid and White, 1919) Chitwood, 1949) on Tomato (Lycopersicon lycopersicum, Mill) Agriculture, Business and Technology Journal 8: 63-67.

Wickramaarachchi, W.A.D.A. and Ranaweera, B. (2008). Effect of Trichoderma viride in Combination with Soil Sterilization and Poultry Manure on the Growth of Capsicum annum Seedlings. Proceedings of $8^{\text {th }}$ Agricultural Symposium, Faculty of Agriculture and Plantation Management, Wayamba University of Sri Lanka. Pp. 253-259.

Zdarska, Z., Huffman, D.G., Moravec, F., Nebesarova, J., (2001). Egg shell Ultrastructure of the fish nematode, Huffmanela Huffman, (Trichosomoididae). Folia Parasitologica 48: 231-234. 